\title{
Emission burden concerns for online shopping returns
}

To the Editor - Customers return products for many reasons. When purchasing from brick and mortar locations, consumers usually return at the same location, and returns represent less than $10 \%$ of products sold. However, online shopping results in a greater number of product exchanges or returns. Although data are not formally compiled, the consensus is that returns from online purchases are double to quadruple that of physical store returns $s^{1,2}$.

Product returns are inefficient from the perspectives of business operations and consumer services, potentially doubling or tripling cost and time as compared with regular deliveries ${ }^{2}$. Furthermore, the inefficiency of reverse logistics activities may generate substantial emissions and resources consumption $^{3,4}$. Meanwhile, research on sustainability and decarbonization of forward supply chains and sales that get the product to the customer ${ }^{4}$ has received much greater attention than has been given to the reverse supply chain of product returns (Fig. 1).

Forward supply chains were designed to be efficient from the very beginning. Studies on the carbon impacts of online shopping and the optimal design of forward supply chains have further improved the efficiency ${ }^{2}$. The research has led to considerable modelling efforts over the years in the design of transportation, facilities, distribution processes and networks that have sought to limit carbon emissions under different regulatory regimes and mechanisms. Greater efficiency and less waste has been occurring with practices such as just-in-time and lean manufacturing ${ }^{5}$.

Reverse supply chains and product returns have been an afterthought - while becoming a 'trillion dollar' problem ${ }^{6}$. Companies evaluate returned products from a business perspective, such as poor customer service and marketing. They do not focus on identifying optimal strategies for returned products and pay even less attention to carbon emissions issues ${ }^{7}$. The inefficiencies and volume of returns can easily equate to well over $30 \%$ of the carbon emissions of the initial deliveries ${ }^{8}$.

Information for product returns related to online shopping supply chains, transport, routes and quantities is insufficient, making it difficult to monitor the carbon emissions of this process. The true value of the environmental burden is thus unknown.

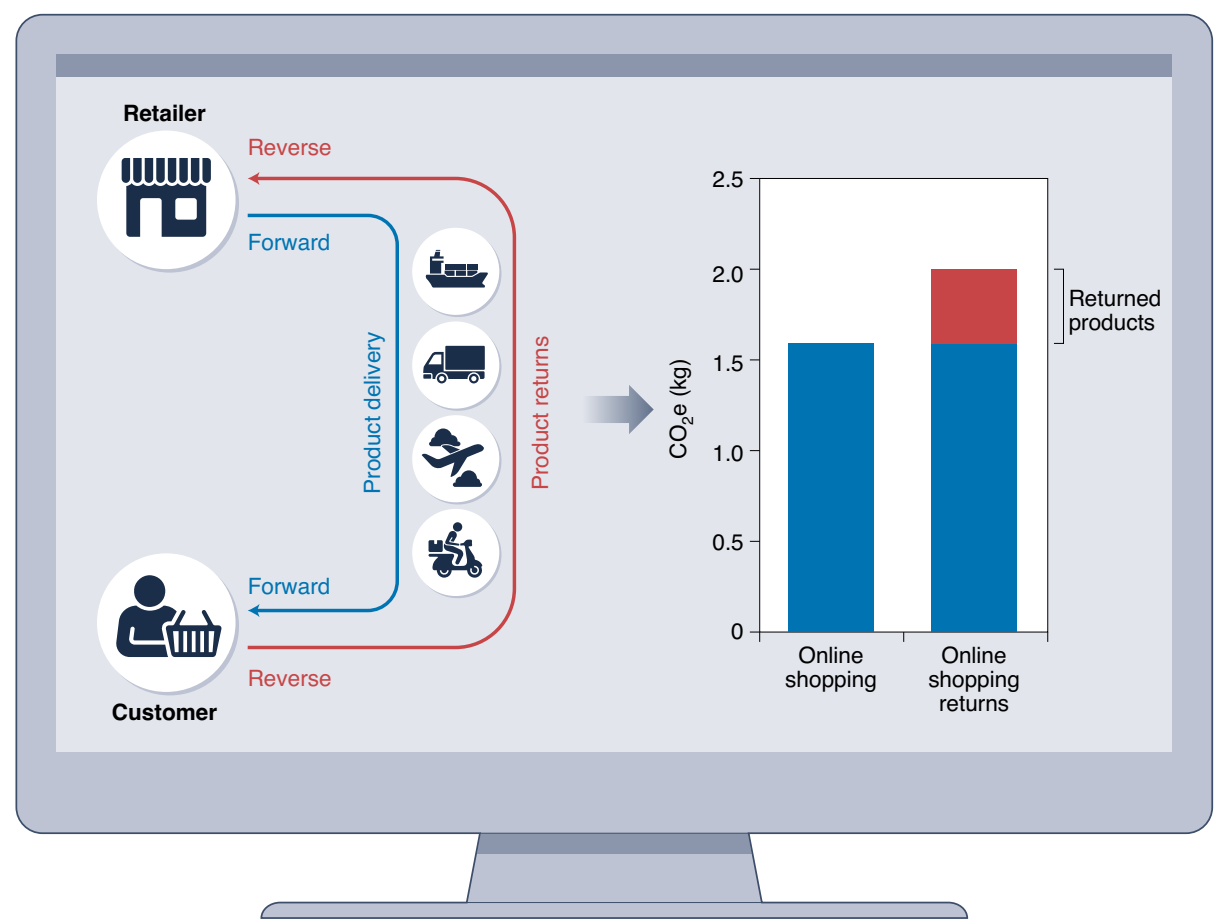

Fig. 1 | Carbon emissions from online shopping and returns. The purchase of products online has carbon emissions implications. Returned products add to these implications and can substantively add to the carbon emissions of online purchases. Careful investigation is needed on product returns in an online environment. Estimated example data are from ref. ${ }^{8}$ and are for the United States.

This is evidenced by the broad range of estimates for returned product values ${ }^{8}$. This is due to reverse supply chains including greater uncertainties in flows and complex processes than forward supply chains, which makes it difficult for empirical research ${ }^{9}$. These difficulties result in a substantial lack of empirical, operational and environmental data with which to calibrate the relevant environmental and product life-cycle models.

Ideally, understanding the reasons for product returns could provide insight into how to manage the related business practices. However, customers return for diverse reasons. It is difficult to identify certain factors and solve them accordingly ${ }^{10}$. For example, sending the wrong products requires different management improvement than if a customer finds that the product does not fit, which make it harder for companies to optimize the efficient reverse supply chain.
Research on the environmental impacts of product returns from online shopping is important but still poorly understood, especially given the continued shift to online shopping due to COVID-19 and digital trade development. We offer some recommendations related to data, corporate practices and consumer practices.

(1) The data quality for product returns need improvement, including better granularity and coverage. Retailers, manufacturers and logistics organizations should cooperate and coordinate data management. Emergent technologies such as block-chain technology could aid this process.

(2) Greater prevention of poor consumer purchasing experiences should be adopted to reduce product returns. Online consumers make their decisions from pictures or videos. Companies should be transparent and realistic 
about qualities such as the aesthetics and performance of products to avoid false expectation.

(3) The environmental awareness of consumers should be raised. Specifically, the relevant environmental information of products could be more explicit on shopping websites. This additional information will be useful for consumers to better understand the overall carbon impact of the products purchased online.

(4) Companies need to more effectively focus on improving the design of reverse supply chains from a carbon emissions perspective. There are potential co-benefits associated with minimizing carbon emissions from product returns and ensuring profitability. Companies should design these reverse logistics networks to improve efficiencies.
Xu Tian (D) 1 and Joseph Sarkis ${ }^{2,3}$ ${ }^{I}$ SJTU-UNIDO Joint Institute of Inclusive and Sustainable Industrial Development, School of International and Public Affairs, Shanghai Jiao Tong University, Shanghai, China. ${ }^{2}$ Worcester Polytechnic Institute, Worcester, MA, USA. ${ }^{3}$ Hanken School of Economics, Humlog Institute, Helsinki, Finland.

$凶_{e-m a i l: t i a n x u @ s j t u . e d u . c n}$

Published online: 23 December 2021

https://doi.org/10.1038/s41558-021-01246-9

\section{References}

1. Thomas, L. More online sales mean retailers need to solve a $\$ 50$ billion returns problem this holiday season. $C N B C$ https:// go.nature.com/3cbsodV (19 December 2019).

2. Edwards, J. et al. Supply Chain Manage. Int. J. 16, 57-63 (2011).

3. Sarkis, J. et al. Supply Chain Manage 9, 303-312 (2004).

4. Kang, P. et al. Nat. Commun. 12, 450 (2021).

5. Fahimnia, B. et al. Int. J. Prod. Econ. 162, 101-114 (2015).
6. Reagan, C. That sweater you don't like is a trillion-dollar problem for retailers. CNBC https://go.nature.com/3DmaAJk (12 January 2019).

7. Shaharudin, M. R. et al. J. Clean. Prod. 101, 1-15 (2015)

8. Weideli, D. \& Cheikhrouhou, N. Environmental Analysis of US Online Shopping (Ecole Polytechnique Fédérale de Lausanne, 2013).

9. Meade, L. et al. Int. J. Logist. Manage. 3, 56-84 (2007).

10. Asdecker, B. et al. Examining drivers of consumer returns in e-tailing with real shop data. In Proc. 50th Hawaii International Conference on System Sciences (2017).

Acknowledgements

This study is supported by the Shanghai Pujiang Program (2020PJC078) and the Natural Science Foundation of China (71704104, 71810107001).

Author contributions

X.T. introduced the concern and idea. Both authors contributed to the writing and revision of this paper.

Competing interests

The authors declare no competing interests. 